\title{
Avaliação de uma intervenção preventiva em motoristas usuários e não usuários de álcool - um estudo piloto
}

\author{
André Luiz Monezi Andrade ${ }^{1}$ \\ Adriana Scatena ${ }^{2}$ \\ Denise De Micheli ${ }^{3}$
}

Neste estudo piloto avaliamos os comportamentos de beber e dirigir e os conceitos de autocrítica sobre este tema em indivíduos que pretendiam dirigir após a saída de bares e restaurantes. Também avaliamos a eficácia de uma intervenção preventiva em seus comportamentos futuros de beber e dirigir. Os participantes tiveram seus níveis de alcoolemia (BAC) avaliados e responderam um questionário, recebendo um folheto informativo durante a intervenção breve. A maioria dos participantes (69\%) apresentaram BAC abaixo dos limites criminais estabelecidos por lei e 31\% acima deste limite. Após um mês, o questionário foi novamente aplicado e não se observou redução significativa no comportamento de beber e dirigir após um mês, indicando a necessidade de intervenções mais efetivas.

Descritores: Intoxicação Alcoólica; Dirigir sob a Influência; Comportamento Perigoso; Serviços Preventivos de Saúde.

\footnotetext{
${ }^{1}$ Pós-doutorando, Universidade Federal de São Paulo, São Paulo, SP, Brasil. Professor Doutor, Universidade Anhembi Morumbi, São Paulo, SP, Brasil.

${ }^{2}$ Mestranda, Universidade Federal de São Paulo, São Paulo, SP, Brasil.

${ }^{3} \mathrm{PhD}$, Professor Adjunto, Universidade Federal de São Paulo, São Paulo, SP, Brasil.
} 


\title{
Evaluation of a preventive intervention in alcoholic and non-alcoholic drivers - a pilot study
}

In this pilot study, we evaluated the drinking and driving behavior and the concepts of selfassessment on this theme of people who had consumed alcohol and intended to drive a motor vehicle after leaving bars and restaurants. We also evaluated the efficacy of a preventive intervention on their future behavior. The participants had their blood alcohol concentration (BAC) evaluated, answered a questionnaire and received a booklet during a very brief intervention. Most of the participants (69\%) had BAC below the legally permitted level, and $31 \%$ above it. One month later, they answered the questionnaire once more and no significant reduction was observed in the use of alcohol before driving after the intervention, indicating the need for more effective interventions.

Descriptors: Alcoholic Intoxication; Driving Under the Influence; Dangerous Behavior; Preventive Health Services.

\section{Evaluación de una intervención preventiva en conductores usuarios y no usuarios de alcohol - un estudio piloto}

\begin{abstract}
En este estudio piloto evaluamos los comportamientos de consumo de alcohol y los conceptos de autocrítica sobre este tema en personas con intención de conducir un vehículo automotor después de salir de bares y restaurantes. También evaluamos la eficacia de una intervención preventiva en comportamiento futuro de beber y conducir. Nosotros evaluamos el nivel de alcoholemia en la sangre (BAC) de los participantes, seguido de un cuestionario. Los participantes también recibieron durante la intervención un prospecto con información acerca del consumo de alcohol e accidentes de tráfico. La mayoría de los participantes (69\%) estaban por debajo de los límites legales de BAC y el $31 \%$ por encima de este límite. Después de un mes, el cuestionario se aplicó de nuevo y no detectamos ninguna reducción en la conducta de beber y conducir, indicando la necesidad de intervenciones más eficaces.
\end{abstract}

Descriptores: Intoxicación Alcohólica; Conducir bajo la Influencia; Conducta Peligrosa; Servicios Preventivos de Salud.

\section{Introduction}

Between the 1970s and 1990s, there was a significant increase in the consumption of alcohol in Brazil. At the middle of the 1990s, the per capita use of alcohol in Brazil was 5.0 liters $^{(1)}$, and currently, it is approximately 8.7 liters $^{(2)}$. The abuse of alcohol can cause a variety of problems, including disorientation, cognitive and motor impairments that lead to accidents and deaths ${ }^{(3)}$. Some authors reported that alcohol misuse is a robust risk factor to disability-adjusted life-years in young people ${ }^{(4)}$. When car accidents are associated with the use of alcohol, the consequences tend to be more severe than with other substances $^{(5)}$. Recently, Peltzer ${ }^{(6)}$ observed that about $17 \%$ of drivers from 22 countries reported having driven after heavily drinking alcohol in the last year. Bangladesh, Indonesia and Kyrgyzstan were the countries with the lowest (about 5\%) and China, Singapore and Thailand with the highest (more than 30\%) number of drunk drivers. In United States, a survey has shown that about $14 \%$ 
of men and $8 \%$ of women have drank before driving in the last 12 months ${ }^{(7)}$.

In Brazil, a survey has shown that in four Brazilian capitals (Brasília, Curitiba, Recife and Salvador) 61.4\% of nonfatal injuries are from traffic accidents (pedestrians and drivers) and $52.9 \%$ of fatal injuries involved alcohol use $^{(8)}$. Furthermore, in $27 \%$ of the cases, the blood alcohol concentration (BAC) was higher than the legal limit. In addition, in four Brazilian cities around 30\% of drivers have already had at least one drinking-anddriving episode in their life ${ }^{(9)}$ and almost $30 \%$ of truck drivers reported having had a binge drinking episode in the last 30 days in the state of São Paulo(10).

This problem does not concern drivers only since positive BAC was detected in $53 \%$ of dead pedestrians and in $50 \%$ of all other victims of car accidents in the city of São Paulo(11). In the city of Porto Alegre, $7 \%$ of drivers and $9.2 \%$ of pedestrians who were involved in serious accidents had positive BAC ${ }^{(12)}$. During some holidays, such as the Brazilian Carnival, alcohol abuse is often involved with serious health and social problems. In the city of Recife, about $80 \%$ of people involved in traffic accidents had positive BAC during the Carnival period(8) and most of them were young people. Regarding this population, adolescents who drank at least one drink (unit) of alcohol increased in four times the chance of getting a ride with a drunk driver and those who consumed more than 5 had five times the chance of being involved in accidents ${ }^{(13)}$.

Until 2008, the limit for BAC in Brazil was 0.6g/l, lower than in the USA and some European countries. According to the new Brazilian legislation, drivers with $0.2 \mathrm{~g} / \mathrm{l} \mathrm{BAC}$ can be fined (administrative penalties) and those with $B A C$ equal to or higher than $0.6 \mathrm{~g} / \mathrm{l}$ can be criminally charged ${ }^{(14)}$. Although Brazil has one of the most restrictive drinking and driving laws, in comparison with previous years, the legislation still has some limitations for suppressing the number of accidents caused by driving under the influence of alcohol(15).

There are a number of primary or secondary strategies of preventive programs to avoid drunk driving, such as designated driving, responsible beverage service and community mobilization ${ }^{(16)}$. These programs could reduce the medical and economic problems derived from alcohol-related accidents if made effective ${ }^{(16)}$. However, there is a lack of programs in Brazil to prevent road traffic deaths that focus on more specific measures than previous programs; the few measures enacted in this regard were limited to sporadic campaigns launched on special dates (e.g., holiday, weekends and Carnival)(15).

Thus, the aim of this study was to evaluate the influence of a brief intervention in drivers who left bars, restaurants and nightclubs regarding their drinking- and-driving behavior. As a secondary measure, we also evaluated alcohol consumption before and after intervention (one month follow-up). We hypothesized that drivers who adhered to the intervention would reduce as their drinking-and-driving behavior as well the number of alcohol units consumed than other participants.

\section{Method}

\section{Participants}

The sample was composed of people who intended to drive after leaving bars, restaurants and pubs in the city of São Paulo. Before they began driving, the researchers approached them explaining the aim of this study. Thus, 178 participants filled the baseline questionnaire, and the final sample was composed of 140 participants that filled the one-month follow-up questionnaire. When more than one person left the location at the same time (e.g., a group of friends), only the designated driver was identified and invited to participate. The participants were recruited near pubs, nightclubs and restaurants from 30 randomly selected locations from three main areas of São Paulo: Center, South and West.

Data collection was performed on Thursdays, Fridays, Saturdays and Sundays between $6 \mathrm{pm}$ and 6am for six consecutive months. Only people who reported having consumed alcohol while still intending to drive a car or ride a motorcycle were included in the study. The project was approved by the Research Ethics Committee of the Universidade Federal de São Paulo (Ethics Committee ID: 0960-02).

\section{Instruments}

We designed a sociodemographic questionnaire composed of 25 questions including topics such as type and number of drinks consumed at the night of the interview, previous involvement in car accidents and their concepts on the risks involved in drinking. The questionnaire was applied immediately after the BAC test. To estimate BAC we used the ALCO SENSOR $®$ IV Intoximeters Breathalyzer and the drivers who had $B A C$ below the legal limit $(B A C<0.6 \mathrm{~g} / \mathrm{l})$ were classified as the non or low-BAC group (NLBAC; N=97) and those with $B A C$ higher to the $0.6 \mathrm{~g} / \mathrm{l}$ limit were classified as the high-BAC group (HBAC; $\mathrm{N}=43$ ).

\section{Procedures}

After receiving an explanation on the purpose and methodology of the study, those who agreed to 
participate signed the informed consent form. The researchers applied the questionnaire immediately after the BAC test and all participants received a feedback on their BAC level and were seriously warned by the researchers about the behavioral risks of drinking and driving. It is worth noting that, according to Brazilian laws, only someone with legal power (like a policeman) can stop a person from drinking and driving. Thus, all participants received a brief intervention (5 to 15 minutes) with the use of normative feedback components. These components were based on previous studies $^{(17)}$ and consisted of an explanation about; 1) how alcohol affects the brain; 2) Brazilian traffic law regarding alcohol consumption; 3 ) how alcohol affects driving capacity; 4) how alcohol can increase the risk of car accidents; 5) the factors that can increase BAC; 6 ) strategies to reduce the effects of alcohol.

The follow-up assessment included data from 140 of the 178 participants, who were contacted approximately 30 days after the interview. Thirty-eight participants could not be contacted due to incorrect telephone number or because they did not want to participate, even after several attempts by the researchers. The contact was performed by phone, and all participants answered a similar questionnaire to the baseline questionnaire with four additional questions related with the impact of our intervention.

\section{Data analysis}

Initially, the numerical variables were transformed into $Z$ score to detect possible outliers, which could impair the reliability of the results. The data below/ above $3(Z$ score $=3<; 3>$ ) were excluded from specific analyses. The Shapiro-Wilk test was performed to evaluate the normality of the data and indicated that a non-parametric test would be necessary to analyze numerical variables. Thus, in order to compare the profile of the participants (HBAC or NLBAC groups), we used the $\mathrm{X}^{2}$ test for categorical variables and the Mann Whitney test or one-way analysis of variance named ANOVA (using the F distribution) for numerical variables.

Based on the statistical recommendations of the American Psychological Association ${ }^{(18)}$, we inserted in the Tables not only the significance level ( $p$ value) but also effect size and $X^{2}$ or $F / U$ values and the confidence interval $( \pm 95 \%)$. For the $X^{2}$ test, effect size was calculated through Cramer's $\vee$ Test based on the degrees of freedom $(d f)$, considering: $d f=1$ ( 0 to $0.1=$ small effect size; 0.11 to $0.3=$ medium effect size; 0.31 to 1 , large effect size); $d f=2$ ( 0 to $0.07=$ small effect size; 0.08 to $0.21=$ medium effect size; 0.22 to 1 , large effect size). Regarding the effect size calculated through the Mann-Whitney test, we used this formula (), considering; $<0.19=$ no significant effect; 0.2 to $0.49=$ small effect; 0.5 to $0.79=$ medium effect; 0.8 to $1.29=$ large effect; $>1.3=$ full effect. Significance level was set at $5 \%$ in all analyses. Statistical analyses were performed using the software Statistica (Statsoft Inc, version 12.0).

\section{Results}

Regarding the sociodemographic data, no differences were detected between the HBAC and NLBAC groups regarding gender, most of the participants of both groups being men (Table 1). Although the HBAC group had slightly more married drivers, significant difference was not observed between the groups. In addition, no significant differences were observed between the groups regarding their educational levels and employment. Most of the drivers reported being undergraduate students and were employed in both groups. Income in NLBAC was higher than in HBAC, $60 \%$ of the former group having reported receiving more than $\$ 2.500 /$ month compared with the latter $(37 \%)$.

Table 2 shows the drinking-and-driving episodes one month after intervention. In the BAC group, almost $40 \%$ of drivers reported not having drunk and driven since intervention compared with the NLBAC group (22\%). More than $60 \%$ of the NLBAC drivers reported having drunk and driven more than 15 days after the followup period. Moreover, $42 \%$ reported having reduced their drinking-and-driving episodes compared with the NLBAC group (29\%).

In addition, no significant differences were observed in both groups regarding the participants' concepts concerning the interference of alcohol on their driving performance. Some changes were detected after the intervention, especially in the NLBAC group in which $86 \%$ of the drivers who had initially declared that alcohol did not interfere on their driving performance considered that drinking could interfere with their driving performance in a significant way during follow-up. When assessing the impact of the informative booklet and if they liked or disliked it, most participants from both groups reported they had read and enjoyed. Table 3 displays the amount of units of alcohol and type of beverages consumed by the drivers before and after intervention. It was observed that the HBAC group slightly increased beer consumption whereas NLBAC reduced whisky consumption after intervention $(p<0.05)$. The Mann-Whitney test did not detect any more differences between the groups. 
Table 1 - Sociodemographic data of individuals with BAC above 0.6g/l (HBAC) and those with BAC below $0.6 \mathrm{~g} / \mathrm{l}$ (NLBAC). Data are expressed as raw and percentage. Sao Paulo, SP, Brazil (2013), (N=140).

\begin{tabular}{|c|c|c|c|c|c|}
\hline & $\operatorname{HBAC}(\mathrm{N}=43)$ & NLBAC $(\mathrm{N}=97)$ & Test & $p$ & Effect size \\
\hline Gender & & & $0.1^{(\mathrm{a})}$ & $0.75^{\text {(a) }}$ & $0.02^{(b)}$ \\
\hline \multirow{2}{*}{ Male } & $33(77 \%)$ & $73(75 \%)$ & & & \\
\hline & $0.61-0.88^{(\mathrm{c})}$ & $0.65-0.83^{(c)}$ & & & \\
\hline \multirow{2}{*}{ Female } & $10(23 \%)$ & $24(25 \%)$ & & & \\
\hline & $0.19-0.48^{(\mathrm{c})}$ & $0.16-0.34^{(\mathrm{c})}$ & & & \\
\hline Marital status & & & $1.21^{(\mathrm{a})}$ & $0.27^{\text {(a) }}$ & $0.09^{(b)}$ \\
\hline \multirow{2}{*}{ Single } & $34(80 \%)$ & $69(71 \%)$ & & & \\
\hline & $0.63-0.89^{\text {(c) }}$ & $0.61-0.8^{(\mathrm{c})}$ & & & \\
\hline \multirow{2}{*}{ Married } & $9(20 \%)$ & $28(29 \%)$ & & & \\
\hline & $0.10-0.36^{(\mathrm{c})}$ & $0.2-0.39^{(c)}$ & & & \\
\hline Educational level & & & & & $0.05^{(b)}$ \\
\hline \multirow{2}{*}{ Primary/High school } & $7(16 \%)$ & $12(12.5 \%)$ & & & \\
\hline & $0.06-0.3^{(\mathrm{c})}$ & $0.06-0.2^{(\mathrm{c})}$ & & & \\
\hline \multirow{2}{*}{ Undergraduate } & $36(84 \%)$ & $85(87.5 \%)$ & & & \\
\hline & $0.69-0.93^{(\mathrm{c})}$ & $0.79-0.93^{(c)}$ & & & \\
\hline Employed & & & $0.32^{(a)}$ & $0.56^{(a)}$ & $0.05^{(\mathrm{b})}$ \\
\hline \multirow{2}{*}{ Yes } & $41(94 \%)$ & $90(92 \%)$ & & & \\
\hline & $0.8-0.95^{(\mathrm{c})}$ & $0.84-0.96^{(c)}$ & & & \\
\hline \multirow{2}{*}{ No } & $2(6 \%)$ & $7(8 \%)$ & & & \\
\hline & $0.01-0.19^{\text {(c) }}$ & $0.03-0.15^{\text {(c) }}$ & & & \\
\hline Income ${ }^{(d)}$ & & & $7.16^{(\mathrm{a})}$ & $0.01^{\text {(a) }}$ & $0.23^{(\mathrm{b})}$ \\
\hline \multirow{2}{*}{$\$ 100-950$} & $9(20.5 \%)$ & $10(10 \%)$ & & & \\
\hline & $0.1-0.36^{(\mathrm{c})}$ & $0.05-0.18^{(\mathrm{c})}$ & & & \\
\hline \multirow{2}{*}{$\$ 950-2500$} & $17(42.5 \%)$ & $27(38 \%)$ & & & \\
\hline & $0.27-0.57^{(\mathrm{c})}$ & $0.29-0.49^{(c)}$ & & & \\
\hline \multirow{2}{*}{ Above $\$ 2500$} & $16(37 \%)$ & $60(62 \%)$ & & & \\
\hline & $0.23-0.53^{(\mathrm{c})}$ & $0.51-0.71^{\text {(c) }}$ & & & \\
\hline
\end{tabular}

${ }^{(a)}$ Chi square test ${ }^{\left({ }^{(b)}\right.}$ Cramer's V test ${ }^{\left({ }^{(}\right)}$The confidence intervals were expressed in percentage divided by $100(\% / 100)$ from $-95 \%$ up to $+95 \%$ (d) Average Real's currency $(R \$)$ value on November 2013; $\$ 1$ dolar= $R \$ 2.322$.

Table 2 - Drinking-and-driving episodes after the intervention period (follow-up) between those with BAC $0.6 \mathrm{~g} / \mathrm{l}$ (HBAC) and those with BAC below 0.6g/l (NLBAC). Data are expressed as raw and percentage. Sao Paulo, SP, Brazil (2013), (N=140).

\begin{tabular}{|c|c|c|c|c|c|}
\hline & $\operatorname{HBAC}(\mathrm{N}=43)$ & NLBAC $(\mathrm{N}=97)$ & Test & $p$ & Effect size \\
\hline Have you drunk and driven since the intervention? & & & $4.41^{\text {(a) }}$ & $0.11^{(\mathrm{a})}$ & $0.17^{(b)}$ \\
\hline \multirow{2}{*}{ No } & $16(37.2 \%)$ & $21(21.6 \%)$ & & & \\
\hline & $0.23-0.53^{(c)}$ & $0.14-0.31^{(\mathrm{c})}$ & & & \\
\hline \multirow{2}{*}{ Yes, in the last 15 days } & $3(7 \%)$ & $14(14.4 \%)$ & & & \\
\hline & $0.01-0.19^{(c)}$ & $0.08-0.23^{(\mathrm{c})}$ & & & \\
\hline \multirow{2}{*}{ Yes, but more than 15 days ago } & $24(55.8 \%)$ & $62(64 \%)$ & & & \\
\hline & $0.4-0.7^{(\mathrm{c})}$ & $0.53-0.73^{(\mathrm{c})}$ & & & \\
\hline $\begin{array}{l}\text { Did you reduce the number of drinking-and-driving } \\
\text { episodes? }\end{array}$ & & & $1.73^{(a)}$ & $0.18^{(a)}$ & $0.12^{(\mathrm{b})}$ \\
\hline \multirow{2}{*}{ No } & $25(58 \%)$ & $69(71 \%)$ & & & \\
\hline & $0.42-0.73^{(c)}$ & $0.61-0.79^{(\mathrm{c})}$ & & & \\
\hline \multirow{2}{*}{ Yes } & $18(42 \%)$ & $28(29 \%)$ & & & \\
\hline & $0.27-0.58^{(\mathrm{c})}$ & $0.2-0.39^{(c)}$ & & & \\
\hline
\end{tabular}

(a)Chi square test ${ }^{\left({ }^{(b)}\right.}$ Cramer's $V$ test ${ }^{\left({ }^{(c)} T h e\right.}$ confidence intervals were expressed in percentage divided by 100 (\%/100) from $-95 \%$ up to $+95 \%$.

\section{Discussion}

The objectives of this pilot study were to evaluate the efficacy of a preventive intervention on drinking-anddriving behavior and the concepts about drinking and driving of drivers who had left bars and restaurants. Most of the drivers from the NBAC group reported that drinking interferes on their driving performance. Nevertheless, they judged that they were fit to drive and indeed did so. This data indicates that the immediate effect of the intervention did not influence their final decision to drive. In addition, a significant reduction in alcohol consumption was not observed. Although many drivers report they do not intend to adopt a risk behavior, they are likely to engage in it even when considering drinking and driving a risk factor ${ }^{(13-14)}$.

Despite some of the drivers interviewed in this study being aware they were intoxicated and believing that 
drinking and driving is a risky behavior, they still did it. Among the reasons associated with this behavior are the lack of adequate public transportation and the fact that taxis are expensive and sometimes difficult to find. Besides, one should consider that intoxicated drivers have their judgment impaired, leading them to believe that "for them" drinking and driving is not a risk behavior. This alteration of self-criticism as well as significant functional deficits may be associated with BAC between 0.1 and $0.5 \mathrm{~g} / \mathrm{l}^{(19)}$.

Most intoxicated drivers reported that drinking did not interfere with their performance but reported the opposite answer after intervention (follow-up period). The decision to drive or not after using alcohol depends on a previous intention that is affected by the self-criticism of drivers concerning the risk involved in this behavior, which might be altered when they are under the effect of

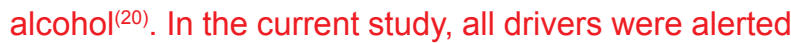
about the risk involved in drinking and driving and how much drinking could affect their performance. According to Brazilian laws, only someone with legal power can stop a person from drinking and driving. Although other people can give advice, they do not have the legal right to stop it. This could be an important issue to be considered in future alterations of the law. Some authors have reported that young Brazilian drivers have very little knowledge on traffic laws and they do not think penalties will be applied to them ${ }^{(9,14)}$.

In addition, we observed that no participants believed that they could be punished if they were assessed on
BAC by a police officer, which also occurs in developed countries ${ }^{(21)}$. Nygaard et al. ${ }^{(22)}$ evaluated the motivations to drive after drinking alcohol in adolescents who admitted to the behavior of drinking and driving and/or had already suffered a car accident after drinking and concluded that an awareness of the lack of systematic surveillance and disregard for the law influenced their decision to drive after drinking. These findings are similar to previous studies in which variables such as being male, having an unfavorable opinion about public policies and excessive use of alcohol during the last year were associated with drinking and driving in $\operatorname{Brazil}^{(9,23)}$.

Although the immediate effect of our intervention was not effective (it did not prevent HBAC participants from driving under the influence of alcohol), interventions which are not merely informative might be more effective. When drivers were asked whether participation in the study changed their drinking-and-driving behavior, many declared that their use of alcohol reduced after participating. The participants from NBAC had lower income than those from the BAC group and some authors observed a relationship between low income and alcohol abuse ${ }^{(7)}$. In Brazil, some authors detected a robust relationship between lower income and alcohol consumption in that $70 \%$ of Brazilian people who earn up to $\$ 500$ per month drink abusively ${ }^{(24)}$. According to the same authors, in the poorest segment of society, $71 \%$ of people drink alcohol, in the lower middle class, $60 \%$ of the people do so, in middle class $56 \%$ and in upper class, $45 \%$.

Table 3 - Number of standard units of alcohol (each unit corresponds to $10 \mathrm{ml}$ or $8 \mathrm{~g}$ of pure ethanol) and type of beverages consumed before and after intervention between those with BAC $0.6 \mathrm{~g} / \mathrm{l}(\mathrm{HBAC})$ and those with BAC below 0.6g/l (NLBAC). Data are expressed as raw and standard deviation ( \pm ). Sao Paulo, SP, Brazil (2013), (N=140).

\begin{tabular}{|c|c|c|c|c|c|}
\hline & Before intervention & Follow up & Test & $p$ & Effect size \\
\hline \multicolumn{6}{|l|}{ Beer } \\
\hline HBAC & $2.1( \pm 1.3)$ & $3( \pm 2.0)$ & $2.82^{(\mathrm{a})}$ & $0.00^{(\mathrm{a})}$ & $0.43^{(\mathrm{b})}$ \\
\hline NLBAC & $4( \pm 2.1)$ & $3.8( \pm 2.1)$ & $1.32^{(\mathrm{a})}$ & $0.18^{(a)}$ & $0.13^{(\mathrm{b})}$ \\
\hline \multicolumn{6}{|l|}{ Wine } \\
\hline HBAC & $2( \pm 1.3)$ & $2.3( \pm 0.2)$ & $1.60^{(\mathrm{a})}$ & $0.10^{(\mathrm{a})}$ & $0.24^{(\mathrm{b})}$ \\
\hline NLBAC & $2( \pm 1.0)$ & $2.7( \pm 0.9)$ & $1.71^{\text {(a) }}$ & $0.11^{(\mathrm{a})}$ & $0.17^{(\mathrm{b})}$ \\
\hline \multicolumn{6}{|l|}{ Whiskey } \\
\hline HBAC & $2( \pm 1.4)$ & $2( \pm 0.8)$ & $1.81^{(\mathrm{a})}$ & $0.21^{(\mathrm{a})}$ & $0.28^{(b)}$ \\
\hline NLBAC & $8( \pm 8.2)$ & $2.5( \pm 0.7)$ & $3.60^{(a)}$ & $0.01^{\text {(a) }}$ & $0.37^{(\mathrm{b})}$ \\
\hline \multicolumn{6}{|l|}{ Vodka } \\
\hline HBAC & $2.5( \pm 0.7)$ & $1( \pm 1.2)$ & $1.61^{(\mathrm{a})}$ & $0.11^{(\mathrm{a})}$ & $0.25^{(\mathrm{b})}$ \\
\hline NLBAC & $2.7( \pm 2.1)$ & $3.7( \pm 2.7)$ & $1.41^{(\mathrm{a})}$ & $0.12^{(\mathrm{a})}$ & $0.14^{(\mathrm{b})}$ \\
\hline \multicolumn{6}{|l|}{ Spirit } \\
\hline HBAC & $1.5( \pm 1.1)$ & $1.6( \pm 0.8)$ & $1.83^{(\mathrm{a})}$ & $0.18^{(\mathrm{a})}$ & $0.28^{(b)}$ \\
\hline NLBAC & $1.3( \pm 0.5)$ & $1.6( \pm 1.2)$ & $1.56^{(\mathrm{a})}$ & $0.19^{(\mathrm{a})}$ & $0.16^{(\mathrm{b})}$ \\
\hline \multicolumn{6}{|l|}{ Ices } \\
\hline HBAC & $2( \pm 1.2)$ & $3( \pm 1.1)$ & $1.76^{(a)}$ & $0.13^{(\mathrm{a})}$ & $0.27^{(\mathrm{b})}$ \\
\hline NLBAC & $2.5( \pm 0.7)$ & $2( \pm 0.2)$ & $1.60^{(\mathrm{a})}$ & $0.12^{(\mathrm{a})}$ & $0.16^{(\mathrm{b})}$ \\
\hline
\end{tabular}

(a) Mann-Whitney test ${ }^{(b)}$ We calculated the effect size of the Mann-Whitney test, by using this formula (), considering; $<0.19=$ no significant effect; 0.2 to $0.49=$ small effect; 0.5 to $0.79=$ medium effect; 0.8 to $1.29=$ large effect; $>1.3=$ full effect. 
This study has limitation such as small sample size because it was a pilot study. Some components of the intervention were probably not effective and the type of the intervention must be adapted to this specific population. In the future, we intend to develop different types of intervention, each with specific components. Another limitation was the lack of a control group which does not allow comparing some of the data from the intervention's effect and the self-criticism on driving under alcohol influence.

\section{Conclusions}

In summary, we observed that people are aware of the risks involved in drinking and driving as well as the interference of alcohol on their performance. However, this information did not promote the expected change in behavior. Another significant factor in São Paulo is the limitation of available transportation in some areas. The limited availability of subway lines, as well as their working hours, the low number of buses in the early hours and the high cost of taxis make it difficult to find an alternative to one's own car. The improvement of preventive programs is necessary with new components that include more effective actions, such as more rigorous surveillance, improvement in driver education and availability of suitable means of transportation.

\section{References}

1. World Health Organization (WHO). Global status report on alcohol. Geneva: WHO, Abuse DoMHaS; 1999.

2. World Health Organization (WHO). The Global status report on alcohol and health Geneva: WHO, Abuse DoMHaS; 2014.

3. Oliveira LG, Leopoldo K, Gouvea MJ, Barroso LP, Gouveia PA, Munoz DR, et al. Prevalence of at-risk drinking among Brazilian truck drivers and its interference on the performance of executive cognitive tasks. Drug Alcohol Depend. 2016;166:218-25.

4. Mokdad AH, Forouzanfar MH, Daoud F, Mokdad AA, El Bcheraoui C, Moradi-Lakeh M, et al. Global burden of diseases, injuries, and risk factors for young people's health during 1990-2013: a systematic analysis for the Global Burden of Disease Study 2013. Lancet. 2016;387(10036):2383-401.

5. Hartman RL, Brown TL, Milavetz G, Spurgin A, Pierce RS, Gorelick DA, et al. Cannabis effects on driving lateral control with and without alcohol. Drug Alcohol Depend. 2015;154:25-37.

6. Peltzer K, Pengpid S. Drinking and Driving among University Students in 22 Low, Middle Income and
Emerging Economy Countries. Iran J Public Health. 2015;44(10):1330-8.

7. White A, Castle IJ, Chen CM, Shirley M, Roach D, Hingson R. Converging Patterns of Alcohol Use and Related Outcomes Among Females and Males in the United States, 2002 to 2012. Alcohol Clin Exp Res. 2015;39(9):1712-26. 8. Nery-Filho A, Medina M, Melcop A, Oliveira E. Impacto do uso de álcool e outras drogas em vítimas de acidentes de trânsito. Brasília (DF): Associação Brasileira dos Departamentos Estaduais de Trânsito. 1997.

9. Campos VR, Souza SR, Duailibi S, Santos JF, Laranjeira $R$, Pinsky I. The effect of the new traffic law on drinking and driving in Sao Paulo, Brazil. Accid Anal Prev. 2013;50:622-7. 10. Leopoldo K, Leyton V, Oliveira LG. Alcohol use alone and in combination with other drugs among truck drivers on highways in Sao Paulo State, Brazil: a cross-sectional study. Cad Saude Publica. 2015;31(9):1916-28.

11. Carlini-Cotrim B, Matta AA. Blood alcohol content and death from fatal injury: a study in the metropolitan area of Sao Paulo, Brazil. J Psychoactive Drugs. 2000;32(3):269-75. 12. Boni R, Bozzetti MC, Hilgert J, Sousa T, Von Diemen L, Benzano D, et al. Factors associated with alcohol and drug use among traffic crash victims in southern Brazil. Accid Anal Prev. 2011;43(4):1408-13.

13. Goncalves PD, Cunha PJ, Malbergier A, Amaral RA, Oliveira LG, Yang JJ, et al. The association between low alcohol use and traffic risk behaviors among Brazilian college students. Alcohol. 2012;46(7):673-9.

14. Andreuccetti G, Leyton V, Carvalho HB, Sinagawa DM, Allen KA, Hyder AA. Drinking and driving in Brazil: same problem, same loophole. Addiction. 2016;111(7):1308-9. 15. Volpe FM, Ladeira RM, Fantoni R. Evaluating the Brazilian zero-tolerance drinking and driving law: Time series analyses of traffic-related mortality in three major cities. Traffic injury prevention. Traffic Inj Prev. In press. 2016.

16. Esser MB, Bao J, Jernigan DH, Hyder AA. Evaluation of the Evidence Base for the Alcohol Industry's Actions to Reduce Drink Driving Globally. Am J Public Health. 2016;106(4):707-13.

17. Shults RA, Elder RW, Nichols JL, Sleet DA, Compton R, Chattopadhyay SK, et al. Effectiveness of multicomponent programs with community mobilization for reducing alcoholimpaired driving. Am J Prev Med. 2009;37(4):360-71.

18. Cumming G, Fidler F, Kalinowski P, Lai J. The statistical recommendations of the American Psychological Association Publication Manual: Effect sizes, confidence intervals, and meta-analysis. Aust J Psychol. 2012;64(3):138-46.

19. Fell JC. The Merits of Adopting a 0.05 Administrative Blood Alcohol Concentration Limit for Driving. Am J Public Health. 2016;106(6):977-8.

20. Bahelah R. What should national alcohol control policies in Muslim majority countries focus on? Addiction. 2016;11(10):1714-5. 
21. Buckley L, Chapman RL, Lewis I. A Systematic Review of Intervening to Prevent Driving While Intoxicated: The Problem of Driving While Intoxicated (DWI). Subst Use Misuse. 2016;51(1):104-12.

22. Nygaard P, Waiters ED, Grube JW, Keefe D. Why do they do it? A qualitative study of adolescent drinking and driving. Subst Use Misuse. 2003;38(7):835-63.

23. Pechansky F, Boni R, Diemen LV, Bumaguin D, Pinsky I, Zaleski $\mathrm{M}$, et al. Highly reported prevalence of drinking and driving in Brazil: data from the first representative household study. Rev Bras Psiquiatr. 2009;31(2):125-30.

24. Caetano R, Mills B, Madruga C, Pinsky I, Laranjeira R. Discrepant trends in income, drinking, and alcohol problems in an emergent economy: Brazil 2006 to 2012. Alcohol Clin Exp Res. 2015;39(5):863-71. 